\title{
EDITORIAL
}

\section{Powder Diffraction Journal December issue and Supplements}

This December issue of Powder Diffraction Journal (PDJ) contains our regular compilation of excellent Technical Articles and New Diffraction Data. These publications come from scientists across the globe and represent an array of materials and materials characterization. In addition to the quarterly PDJ publication schedule, supplemental issues are produced that allow for highlighting international conferences and selected topics of interest to the diffraction and scattering communities.

Proceedings of the 2014 Australian X-ray Analytical Association (AXAA) have been published as one of these PDJ Supplements and available online by accessing the Cambridge University Press website (see below). The Editors for the AXAA papers are Nathan Webster and Vanessa Peterson. Access is free to online subscribers of
Powder Diffraction as well as attendees of the 2014 AXAA Conference that was held in Perth, Australia.

For December there is a second supplemental issue, covering the topic of XRD Software, with Brian Toby as Editor. Articles covering current topics in software including the first publication describing DICVOL14, the newest version of this popular indexing program, are presented. This XRD Software PDJ issue will also be published online only. Upon agreement from the publisher, this supplement will be available as free access for 1 year.

To view PDJ through the Cambridge University Press website use the following web address: http://journals.cambridge.org/action/displayJournal?jid=PDJ

Tom Blanton

ICDD Principal Scientist and Database Manager 